\title{
Special Session: Looking for a New \\ Research Partner: Find your Perfect \\ "Researcher Match": An Abstract
}

\author{
Janna Parker and Hyunju Shin
}

\begin{abstract}
After completing a doctoral program, many researchers find that they need to find new research collaborators. Their former professors will have new students to mentor, and at small institutions, they may not find colleagues with similar research interests. Conferences can provide networking opportunities to assist with solving this problem. Yet, sometimes, conditions may make it difficult for these connections to occur.

The purpose of this special session is to provide an opportunity for researchers, and specifically those who are new to the field, to connect with other researchers who share an interest in specific areas. Researchers will select two topics of interest as they arrive. The session will be composed of three rounds in which all will participate in "research circles" with other interested researchers. Groups will be formed for e-commerce, social media, advertising and IMC, consumer behavior, ethics and sustainability, nonprofit and public policy, services and retailing, and branding, among others. The goal of this special session is to facilitate the making of new research-related connections.
\end{abstract}

Keywords Research $\cdot$ Marketing research $\cdot$ Special session $\cdot$ Networking

References Available Upon Request

\author{
J. Parker $(\square)$ \\ James Madison University, Harrisonburg, VA, USA \\ e-mail: parke4jm@jmu.edu \\ H. Shin \\ Georgia Southern University, Statesboro, GA, USA \\ e-mail: hshin@georgiasouthern.edu
}

(C) The Academy of Marketing Science 2020

$\mathrm{S}$. Wu et al. (eds.), Marketing Opportunities and Challenges in a Changing Global Marketplace, Developments in Marketing Science: Proceedings of the

Academy of Marketing Science, https://doi.org/10.1007/978-3-030-39165-2_122 